\title{
Widely Tunable High-Power Tapered Diode Laser at 1060 nm
}

\author{
Jensen, Ole Bjarlin; Sumpf, Bernd; Erbert, Götz; Petersen, Paul Michael
}

Published in:

I E E E Photonics Technology Letters

Link to article, DOI:

10.1109/LPT.2011.2165702

Publication date:

2011

Document Version

Peer reviewed version

Link back to DTU Orbit

Citation (APA):

Jensen, O. B., Sumpf, B., Erbert, G., \& Petersen, P. M. (2011). Widely Tunable High-Power Tapered Diode Laser at $1060 \mathrm{~nm}$. I E E E Photonics Technology Letters, 23(21), 1624-1626.

https://doi.org/10.1109/LPT.2011.2165702

\section{General rights}

Copyright and moral rights for the publications made accessible in the public portal are retained by the authors and/or other copyright owners and it is a condition of accessing publications that users recognise and abide by the legal requirements associated with these rights.

- Users may download and print one copy of any publication from the public portal for the purpose of private study or research.

- You may not further distribute the material or use it for any profit-making activity or commercial gain

- You may freely distribute the URL identifying the publication in the public portal

If you believe that this document breaches copyright please contact us providing details, and we will remove access to the work immediately and investigate your claim. 


\title{
Widely Tunable High Power Tapered Diode Laser at $1060 \mathrm{~nm}$
}

\author{
Ole Bjarlin Jensen, Bernd Sumpf, Götz Erbert, Member, IEEE, and Paul Michael Petersen
}

\begin{abstract}
We report a large tuning range from $1018 \mathrm{~nm}$ to $1093 \mathrm{~nm}$ from a InGaAs single quantum well $1060 \mathrm{~nm}$ external cavity tapered diode laser. More than $2.5 \mathrm{~W}$ output power has been achieved. The tuning range is to our knowledge the widest obtained from a high power InGaAs single quantum well tapered laser operating around $1060 \mathrm{~nm}$. The light emitted by the laser has a nearly diffraction limited beam quality and a narrow line width of less than $6 \mathrm{pm}$ everywhere in the tuning range.
\end{abstract}

Index Terms-Semiconductor lasers, quantum well lasers, tapered lasers, laser tuning.

\section{INTRODUCTION}

High power narrow line width diode lasers in the $1060 \mathrm{~nm}$ spectral region are of interest for many applications including spectroscopy and frequency conversion to the green spectral range [1]. The tapered diode lasers are currently attracting an increasing amount of interest as they combine high output power with good beam quality [2].

High power near diffraction limited tapered diode lasers have been realized at many operating wavelengths with a main focus on the red to near infrared spectral range $[3,4]$. For many applications narrow line width operation is required and various techniques have been investigated to achieve this. Different external cavity approaches including the use of diffraction gratings [5] and Bragg gratings [6,7] have been investigated as well as injection seeding using a low power narrow line width seed laser [8].

Recently, DBR tapered diode lasers have shown high output power and narrow line width operation and the simplicity and robustness makes this approach very attractive $[9,10]$. For some applications, however, tuning of the output wavelength is required and injection seeding or external cavity techniques can be used. In the 1000-1100 nm wavelength range, tunable, near diffraction limited external cavity tapered diode lasers have been developed with high output power of 4 $\mathrm{W}$ [7] and also large tuning ranges of up to $65 \mathrm{~nm}$ have been obtained [11]. An injection seeded tapered diode laser with an output power of up to $7.4 \mathrm{~W}$ at $1083 \mathrm{~nm}$ has been demonstrated [8].

Manuscript received May 13, 2011. This project was supported by the EUFP6 integrated project WWW.BRIGHTER.EU contract IST-2005-035266.

O. B. Jensen and P. M. Petersen are with DTU Fotonik, Department of Photonics Engineering, Technical University of Denmark, Frederiksborgvej 399, 4000 Roskilde, Denmark (e-mail: ojen@fotonik.dtu.dk).

B. Sumpf and G. Erbert are with Optoelectronics Department, FerdinandBraun-Institut, Leibniz-Institut für Höchstfrequenztechnik, Gustav-KirchhoffStraße 4, 12489 Berlin, Germany.
Here, we present the operation of a tunable, near diffraction limited external cavity tapered diode laser with an output power of up to more than $2.5 \mathrm{~W}$ and a wide tuning range of $75 \mathrm{~nm}$ centered around $1060 \mathrm{~nm}$. To our knowledge this is the widest tuning range for an external cavity tapered diode laser in this wavelength region. Narrow line width operation is obtained over the entire tuning range.

\section{EXPERIMENTAL SETUP}

The tapered amplifier used in the experiments has a total length of $4 \mathrm{~mm}$ divided between a $1 \mathrm{~mm}$ long index guided single-mode ridge waveguide section and a $3 \mathrm{~mm}$ long gain guided tapered amplifier section. The taper angle for the amplifier is $4^{\circ}$ resulting in an output aperture width of $210 \mu \mathrm{m}$.

The tapered amplifier is grown by metal-organic vapor phase epitaxy (MOVPE). The active region of the amplifier consists of a single $7 \mathrm{~nm}$ thick $\mathrm{In}_{0.25} \mathrm{Ga}_{0.75} \mathrm{As}$ quantum well (SQW). The active region is embedded in a $3.6 \mu \mathrm{m}$ thick $\mathrm{Al}_{0.25} \mathrm{Ga}_{0.75} \mathrm{As}$ waveguide and $500 \mathrm{~nm}$ thick $\mathrm{Al}_{0.5} \mathrm{Ga}_{0.5} \mathrm{As}$ cladding layers. The layer sequence is completed by a highly doped GaAs contact layer. The layer structure is shown in the inset of Fig. 1. The vertical far field angle of this super large optical cavity structure (SLOC) [12] is about $22^{\circ}$ (FWHM). The slow axis far field angle from the back facet is smaller than $20^{\circ}\left(1 / \mathrm{e}^{2}\right)$.

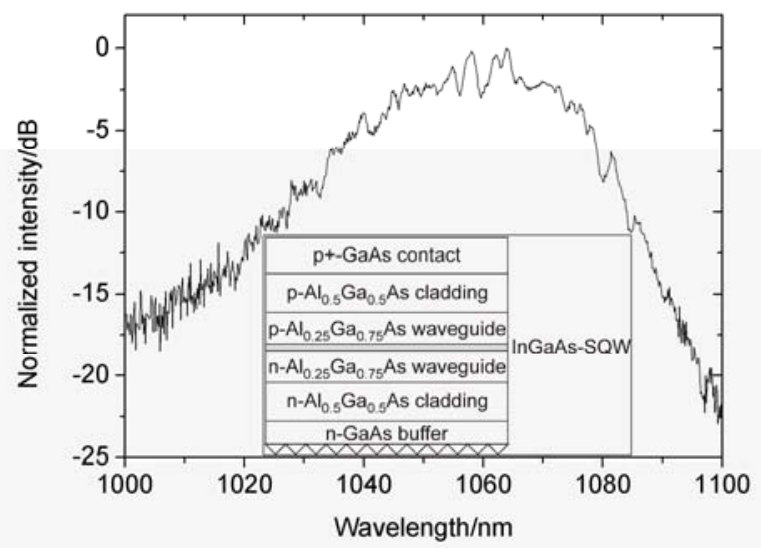

Fig. 1. Free running spectrum for the tapered amplifier at $2 \mathrm{~A}$ drive current and a temperature of $25^{\circ} \mathrm{C}$. The inset shows the layer structure of the amplifier.

The facets of the device were passivated [13] and after this optically coated. The rear facet of the amplifier is 
antireflection coated with a reflectivity below $0.1 \%$ while the front facet is coated to a reflectivity of $2 \%$.

The device was mounted p-side down on a $\mathrm{CuW}$ submount using AuSn solder and soldered on a standard C-mount.

The emission spectrum of the free running tapered amplifier, i.e. without external grating feedback, at $2 \mathrm{~A}$ drive current and $25^{\circ} \mathrm{C}$ temperature is given in Fig. 1. The center of the emission is at $1059 \mathrm{~nm}$ and $99 \%$ of the emission is originated from a spectral width of $85 \mathrm{~nm}$.

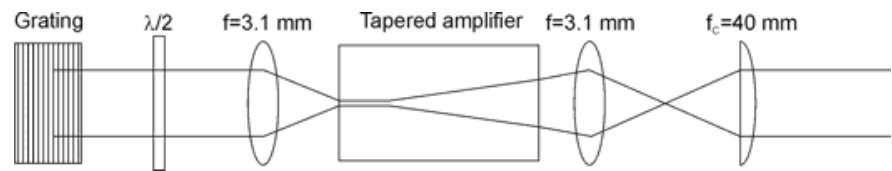

Fig. 2. Sketch of the experimental setup for the external cavity tapered diode laser. $\lambda / 2$ is a half wave plate.

The tapered amplifier described above has been operated in an external cavity. A simplified sketch of the external cavity is given in Fig. 2. The beam emitted from the back facet of the tapered amplifier is collimated in both the fast and slow axes using an aspherical lens with a focal length of $3.1 \mathrm{~mm}$ and a numerical aperture (NA) of 0.68 . The diffraction grating is ruled with 1200 grooves $/ \mathrm{mm}$ and is blazed for $1000 \mathrm{~nm}$. A half wave plate is inserted before the diffraction grating in order to rotate the polarization by $90^{\circ}$ for maximum diffraction efficiency of the grating, which is about $85 \%$. The grating is operated in the Littrow configuration and the grating lines are parallel to the active region of the amplifier in order to achieve better frequency discrimination. The output from the external cavity laser is collimated in the fast axis using a $3.1 \mathrm{~mm}$ focal length aspherical lens with a NA of 0.68. A cylindrical lens with a focal length of $40 \mathrm{~mm}$ is used to collimate the slow axis beam and simultaneously compensate for astigmatism.

\section{EXPERIMENTAL RESULTS}

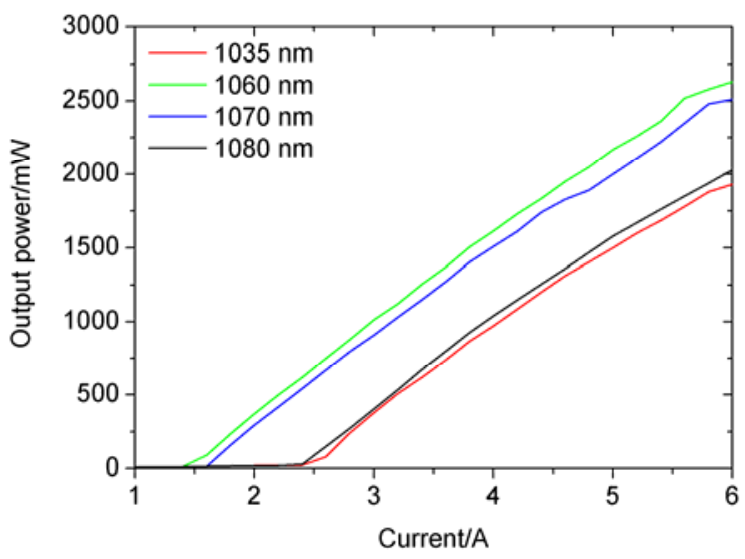

Fig. 3. Power-current characteristics for the external cavity tapered diode laser system at different wavelengths within the tuning range.
The power characteristics for the external cavity laser are shown in Fig. 3, at an operating temperature of $20^{\circ} \mathrm{C}$ and at different wavelengths.

The maximum achieved output power is $2.63 \mathrm{~W}$ at $6 \mathrm{~A}$ drive current at a wavelength of $1060 \mathrm{~nm}$ limited by the available current from the power supply and by thermal roll over. At low currents, the slope efficiency of the laser is in the range between $0.59 \mathrm{~W} / \mathrm{A}$ and $0.64 \mathrm{~W} / \mathrm{A}$ depending on the wavelengths. For the wavelength close to the maximum of the free running spectrum (see Fig. 1), the threshold is about 1.5 A. This value increases to $2.5 \mathrm{~A}$ for the wavelengths in the wings of the spectrum. Moreover, measurements of the amplified spontaneous emission for this material show that the spectral position and width of the gain curve is independent from the excitation current. This is due to the compensation between the blue shift caused by the strong band filling and the red shift caused by the thermal heating with increasing current.

The beam quality of the external cavity tapered diode laser in the slow axis is determined by measuring the beam quality parameter $\mathrm{M}^{2}$ at different output powers. A spherical lens with a focal length of $80 \mathrm{~mm}$ is used to focus the output beam. The beam diameter $\left(1 / \mathrm{e}^{2}\right)$ is measured at various distances along the optical axis. The $\mathrm{M}^{2}$ value is obtained by fitting the measured values to a hyperbola. The measurement is performed at different driving currents and wavelengths to evaluate the change in beam quality with output power and the result is given in Fig. 4 at wavelengths of $1035 \mathrm{~nm}, 1060 \mathrm{~nm}$, $1070 \mathrm{~nm}$ and $1080 \mathrm{~nm}$. The $\mathrm{M}^{2}$ values did not change significantly within the tuning range.

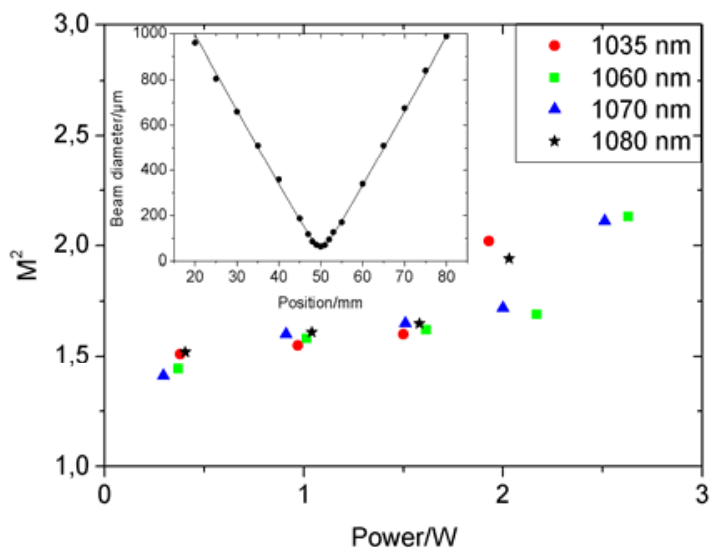

Fig. 4. Measured beam quality parameter $\mathrm{M}^{2}$ at different driving currents for the external cavity tapered laser. The inset shows the measured beam width at an output power of $2.2 \mathrm{~W}$ at $1060 \mathrm{~nm}$.

The $\mathrm{M}^{2}$ of the external cavity tapered laser at wavelengths around the gain maximum stays below 1.7 up to $2.2 \mathrm{~W}$ output power and increases to 2.15 at maximum output power. At 2.2 W output power, approximately $80 \%$ of the power is contained in the central lobe of the beam. For this working point, the beam quality data using the $1 / \mathrm{e}^{2}$ method and the second moments were determined. The $\mathrm{M}^{2}\left(1 / \mathrm{e}^{2}\right)$ was 1.7 and the $\mathrm{M}^{2}(4 \sigma)$ was determined to 2.1 . This compares favorably to the beam quality of $\mathrm{M}^{2}<1.4$ at $1 \mathrm{~W}$ output power reported by 
Kelemen et al. [11]. The increase at maximum output power is caused by higher order modes beginning to oscillate and thus increasing the focus size. During the measurements, the position of the cylindrical lens is shifted along the optical axis to account for the change in astigmatism occurring when the current of the laser is increased. The inset of Fig. 4 shows the measured beam width for the laser at $2.2 \mathrm{~W}$ output power at a wavelength of $1060 \mathrm{~nm}$.

Wavelength tuning of the external cavity tapered diode laser is realized by rotating the diffraction grating. In Fig. 5 the tuning characteristics of the laser are given. In the experiments, the temperature is kept constant at $20^{\circ} \mathrm{C}$ and the current is $5 \mathrm{~A}$.

The full tuning range of the external cavity tapered laser ranges from $1018-1093 \mathrm{~nm}$ while the FWHM tuning range is $1027-1086 \mathrm{~nm}$ with an output power of more than $1 \mathrm{~W}$.

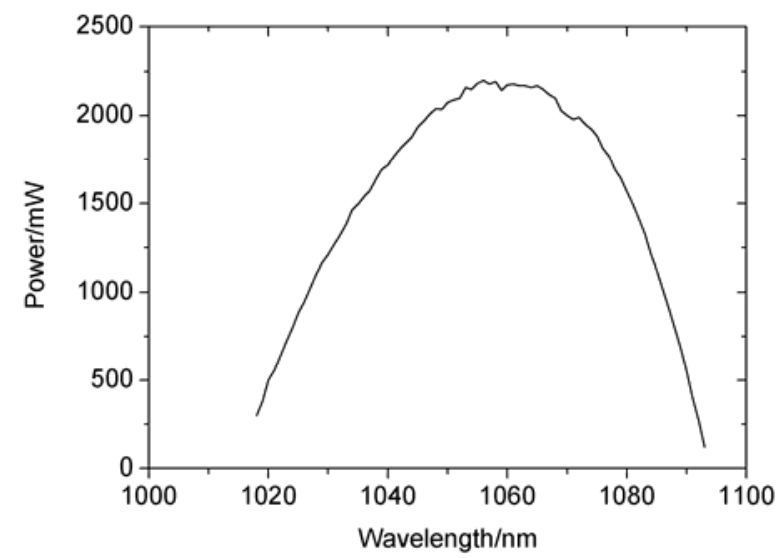

Fig. 5. Wavelength tuning characteristics for the external cavity tapered diode laser at an operating temperature of $20^{\circ} \mathrm{C}$ and $5 \mathrm{~A}$ current.

The spectral line width of the laser is measured using an optical spectrum analyzer (Advantest Q8347) with a resolution limit of $6 \mathrm{pm}$. The spectral width (FWHM) of the laser is below the resolution limit throughout the tuning range of the laser at a current of $5 \mathrm{~A}$, and the amplified spontaneous emission is suppressed by more than $30 \mathrm{~dB}$ limited by the dynamic range of the optical spectrum analyzer. Example spectra are given in Fig. 6 at wavelengths of $1035 \mathrm{~nm}, 1060$ $\mathrm{nm}, 1070 \mathrm{~nm}$ and $1080 \mathrm{~nm}$.

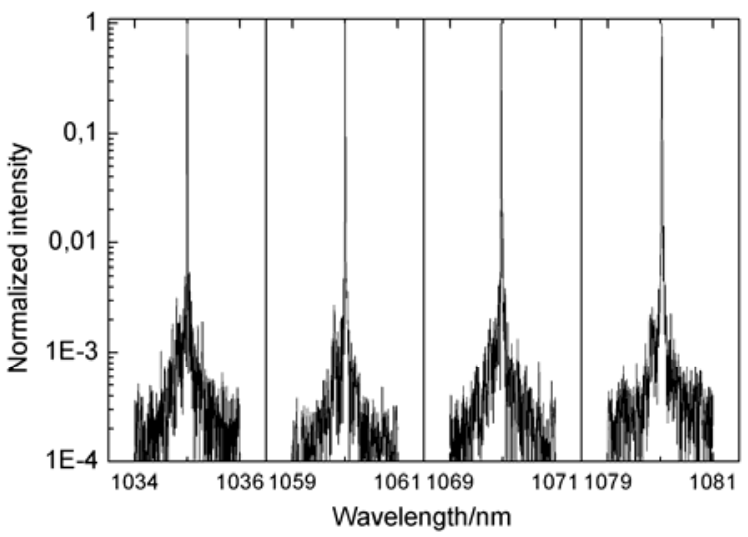

Fig. 6. Four spectra obtained for the external cavity tapered diode laser obtained at $20^{\circ} \mathrm{C}$ operating temperature and $5 \mathrm{~A}$ driving current.

At maximum output power the spectral width increases and is in the range $30-100 \mathrm{pm}$ with the largest line width measured at the long wavelengths of the tuning range. This could possibly be attributed to higher thermal load, less gain for the longest wavelengths or a possible slight misalignment of the external cavity.

\section{CONCLUSION}

We have demonstrated a widely tunable external cavity tapered diode laser system around $1060 \mathrm{~nm}$. More than $2.5 \mathrm{~W}$ of output power in a nearly diffraction limited output beam has been achieved. A wide tuning range of $75 \mathrm{~nm}$ has been demonstrated from $1018 \mathrm{~nm}$ to $1093 \mathrm{~nm}$. This is to our knowledge the widest tuning range obtained from an external cavity tapered diode laser system in this wavelength range.

\section{REFERENCES}

[1] O. B. Jensen, P. E. Andersen, B. Sumpf, K.-H. Hasler, G. Erbert, and P. M. Petersen, " $1.5 \mathrm{~W}$ green light generation by single pass second harmonic generation of a single-frequency tapered diode laser," Opt. Express, vol. 17, pp. 6532-6539, 2009.

[2] "Tapered Triumph," Nature Photon., vol. 3, pp. 24-25, 2009.

[3] B. Sumpf, H. Wenzel, and G. Erbert, "High-power, high-brightness semiconductor tapered diode lasers for the red and near infrared spectral range," Proc. SPIE, vol. 7716, pp. 77161L, 2010.

[4] J. N. Walpole, "Semiconductor amplifiers and lasers with tapered gain regions," Opt. Quantum Electron., vol. 28, pp. 623-645, 1996.

[5] M. Chi, O. B. Jensen, J. Holm, C. Pedersen, P. E. Andersen, G. Erbert, B. Sumpf, and P. M. Petersen, "Tunable high-power narrow-linewidth semiconductor laser based on an external-cavity tapered amplifier," Opt. Express, vol. 13, pp. 10589-10596, 2005.

[6] G. Lucas-Leclin, D. Paboeuf, P. Georges, J. Holm, P. Andersen, B. Sumpf, and G. Erbert, "Wavelength stabilization of extended-cavity tapered lasers with volume Bragg gratings,"Appl. Phys. B, vol. 91, pp. 493-498, 2008

[7] R. Ostendorf, C. Schilling, G. Kaufel, R. Moritz, J. Wagner, G. Kochem, P. Friedmann, J. Gilly, and M. T. Kelemen, "High-power frequency stabilized tapered diode amplifiers at 1064 nm, " Proc. SPIE, vol. 7198, pp. 719811, 2009.

[8] S. Schwertfeger, J. Wiedmann, B. Sumpf, A. Klehr, F. Dittmar, A. Knauer, G. Erbert, and G. Tränkle, "7.4 W continuous-wave output power of master oscillator power amplifier system at $1083 \mathrm{~nm}$,“ Electron. Lett., vol. 42, pp. 346-347, 2006.

[9] K.-H. Hasler, B. Sumpf, P. Adamiec, F. Bugge, J. Fricke, P. Ressel, H. Wenzel, G. Erbert, and G. Tränkle, "5-W DBR tapered lasers emitting at $1060 \mathrm{~nm}$ with a narrow spectral linewidth and a nearly diffractionlimited beam quality, “ IEEE Photon. Technol. Lett. vol. 20, pp. 16481650,2008

[10] B. Sumpf, K.-H. Hasler, P. Adamiec, F. Bugge, J. Fricke, P. Ressel, H. Wenzel, G. Erbert, and G. Tränkle, "1060 nm DBR tapered lasers with $12 \mathrm{~W}$ output power and a nearly diffraction limited beam quality, " Proc. SPIE, vol. 7230, pp. 72301E, 2009.

[11] M. T. Kelemen, J. Weber, F. Rinner, J. Rogg, M. Mikulla, and G. Weimann, "High-brightness $1040 \mathrm{~nm}$ tapered diode lasers," Proc. SPIE, vol. 4947 , pp. 252-260, 2003.

[12] A. Knauer, G. Erbert, R. Staske, B. Sumpf, H. Wenzel, and M. Weyers, "High-power 808-nm lasers with a super-large optical cavity," Semicond. Sci. Technol., vol. 20, pp. 621-624, 2005.

[13] P. Ressel, G. Erbert, U. Zeimer, K. Häusler, G. Beister, B. Sumpf, A Klehr, and G. Tränkle, „Novel passivation process for the mirror facets of high-power semiconductor diode lasers," IEEE Photon. Technol. Lett., vol. 17, pp. $962-964,2005$. 